\title{
Farklı Döşeme Tiplerine Sahip Betonarme Binaların Sismik Davranışı
}

\author{
Başak Zengin ${ }^{1}$, Pınar Usta ${ }^{2 *}$ \\ 1* Nişamtaşı Üniversitesi, Mimarlık ve Mühendislik Fakültesi, İnşaat Mühendisliği Bölümü, Istanbul, Türkiye, (ORCID: 0000-0003-3719-9423), \\ zenginbasak@gmail.com \\ 2* Isparta Uygulamalı Bilimler Üniversitesi, Teknoloji Fakültesi, İnşaat Mühendisliği Bölümü, Isparta, Türkiye (ORCID: 0000-0001-9809-3855), \\ pinarusta@isparta.edu.tr
}

(İlk Geliş Tarihi 1 Haziran 2021 ve Kabul Tarihi 21 Ağustos 2021)

(DOI: 10.31590/ejosat.946539)

ATIF/REFERENCE: Basak, Z., \& Usta, P. (2021). Farklı Döşeme Tiplerine Sahip Betonarme Binaların Sismik Davranışı. Avrupa Bilim ve Teknoloji Dergisi, (27), 171-176.

Öz

$\mathrm{Bu}$ çalışmada döşeme tipinin betonarme bina davranışına etkisini incelemek için betonarme bir çerçeveli bina plak döşeme ve tek doğrultuda çalışan dişli döşemeli olarak SAP2000 V21 programı ile modellenmiştir. Binanın deprem hesabı için Türkiye Bina Deprem Yönetmeliği (2008)' de tanımlanan Deprem Düzeyi 2 seviyesine göre yapay deprem kaydı üretilmiştir. Üretilen deprem kaydı ile farklı iki tip döşemeye sahip binanın zaman tanım alanında doğrusal hesabı yapılmış ve binalara ait kat kesme kuvvetleri, kat öteleme değerleri, kat rijitlikleri, maksimum yer değiștirme değerleri elde edilmiştir. Nervürlü döșeme binasının deprem yüklerine karşı performansının plak döşemeye göre daha düşük olduğu görülmüştür. Deprem riski yüksek bölgelerde nervürlü döşeme sahip bina kullanımına dikkat edilmesi gerektiği, Özelikle tek doğrultuda çalışan dişli döşemeye sahip mevcut binaların mevcut yönetmeliklere göre yeniden ele alınması gerektiği bu çalışma ile ortaya konulmaya gayret edilmiştir.

Anahtar Kelimeler: Döşeme tipi, Bina Davranışı, Deprem.

\section{Seismic Analysis of Different Slab Types for Reinforced Concrete Structures}

\begin{abstract}
In this study, a reinforced concrete framed building was modeled with slab slab and unidirectional gear slab with the SAP2000 V21 program to examine the effect of slab type on the behavior of reinforced concrete buildings. For the earthquake calculation of the building, an artificial earthquake record was produced according to the Earthquake Level 2 level defined in the Turkish Building Earthquake Code (2008). With the earthquake record produced, linear calculations were made in the time history of the building with two different types of flooring, and the floor shear forces, floor drift values, floor stiffnesses, and maximum dis placement values of the buildings were obtained. It has been observed that the performance of the ribbed slab building against earthquake loads is lower than that of the plate slab. It has been tried to reveal that the use of buildings with ribbed floors in areas with high earthquake risk should be considered, especially existing buildings with single-sided gear flooring should be reconsidered according to current regulations with the present study.
\end{abstract}

Keywords: Slab type, Building behavior, Earthquake.

*Sorumlu Yazar: zenginbasak@gmail.com 


\section{Giriş}

Şiddetli deprem tehlikesi altında bulunan ülkelerden birisidir. Türkiye'de bulunan yapılar yıllardır bulundukları yer itibari ile çok sayıda depreme maruz kalmıştır. Özellikle son depremlerde birçok betonarme yapının ciddi şekilde hasar gördüğü veya çöktüğü görülmüşsür. Bu durum mevcut binaların ve yeni yapılacak binaların sismik yeterliliğinin detaylıca değerlendirilmesi ihtiyaç olduğunu göstermektedir. Türkiye'de son yüzyıl içerisinde büyüklüğü 6 ve daha fazla olan deprem sayıs1 56'dır. Meydana gelen bu depremler sonucunda ortaya çıkan hasarlar oldukça fazladır. Öyle ki; depremler sonrası hasarların karşılanması için her yıl milli gelirimizin \%0.8'i kullanılmaktadır (Usta ve Bozdağ, 2021). Bu depremlerden önemli birkaçı Tablo 1'de verilmiştir.

Tablo 1. Son Yillarda Türkiye'de meydana gelen depremlerden bazıları (Aral ve Tunç, 2021)

\begin{tabular}{lllll}
\hline Bölge & Tarih & $\begin{array}{l}\text { Lokal } \\
\text { Mag. } \\
\mathbf{M}_{\mathbf{L}}\end{array}$ & $\begin{array}{l}\text { Can } \\
\text { Kaybı }\end{array}$ & $\begin{array}{l}\text { Yaralı } \\
\text { Sayısı }\end{array}$ \\
\hline $\begin{array}{l}\text { Şenkaya/Erzurum } \\
\text { Sarıkamış/Kars }\end{array}$ & 30.10 .1983 & 6.6 & 1.115 & 537 \\
\hline Erzincan & 13.03 .1992 & 6.6 & 653 & 3.850 \\
\hline $\begin{array}{l}\text { Dinar, Evciler } \\
\text { (Afyon) }\end{array}$ & 01.10 .1995 & 5.9 & 90 & 240 \\
\hline $\begin{array}{l}\text { Salhançayı } \\
\text { (Çorum-Amasya) }\end{array}$ & 14.08 .1996 & 5.4 & 0 & 0 \\
\hline Ceyhan (Adana) & 28.06 .1998 & 6.2 & 145 & 1.500 \\
\hline Gölcük (Kocaeli) & 17.08 .1999 & 7.6 & 17.480 & 23.781 \\
\hline Düzce-Bolu & 12.11 .1999 & 7.2 & 710 & 2.679 \\
\hline $\begin{array}{l}\text { Sultandağ1 } \\
\text { (Afyon) }\end{array}$ & 03.02 .2002 & 6.5 & 42 & 150 \\
\hline Merkez (Bingöl) & 01.05 .2003 & 6.4 & 176 & 520 \\
\hline Simav (Kütahya) & 19.05 .2011 & 5.7 & 2 & 79 \\
\hline Merkez (Van) & 23.10 .2011 & 6.7 & 644 & 1.966 \\
\hline Sivrice (Elazı̆g) & 24.01 .2020 & 6.8 & 44 & 1.607 \\
\hline İzmir ve çevresi & 20.10 .2020 & 6.6 & 115 & 1.035 \\
\hline
\end{tabular}

Yıllar geçtikçe, betonarme binalar daha ince ve daha hafif bir forma dönüşmüş dolayısıyla da deprem, rüzgar gibi sismik titreşimlere daha duyarlı hale gelmiştir (Middleton ve Bownjohn, 2010). Özellikle son depremlerde birçok betonarme binanın ciddi şekilde hasar gördüğü veya çöktüğü görülmüştür. Bu durum mevcut binaların ve yeni yapılacak binaların sismik yeterliliğinin detaylıca değerlendirme ihtiyacına işaret etmiştir.

Döşeme, binanın ana yükünü alan, bina sakinleri ile doğrudan temas halinde olan ve bu nedenle titreşime maruz kalan, ilave sabit ve hareketli yükleri taşıyan yapısal elemanlardır. (Costa ve Araújo, 2014; Arman, 2014). Binadaki düşey ve yatay yükleri (deprem vb.) binaların düşey taşıyıcı elemanlarına aktaran döşemeler kalınlıkları diğer iki boyutu yanınada ihmal edilebilir, bu nedenle iki boyutlu olarak kabul edilebilir. Ayrıca, aynı katların eşit yerdeğiştirme ve dönme yapmalarını sağlamaları nedeniyle, analizlerde dikkate alınan rijit diyafram kabulünü destekleyen elemanlardır. Döşeme elemanları binalar, yollar ve köprülerde kullanılmaktadır (Bikçe ve Akyol, 2017).

Nervürlü döşemeler birbirine yakın aralıklı kiriş serisi ile dökülen ve bir dizi kiriş tarafindan desteklenen döşemelerdir. Nervürlü döşemelerde tarafsız eksenin altındaki betonun bir kısmının kaldırılması ile ağırlıkta azalma olmaktadır. Nervürlü döşemeler hafif veya orta ağırlıklı binalarda ekonomik çözüm sağlamaktadır (Malviya ve Tiwari, 2020). Nervürlü döşemeler, düz levhaya kıyasla daha hafif ve daha sert bir levhadır. Levha titreşiminin bir sorun olduğu yerlerde çok mükemmel çalışırlar. Nervürlü döşeme bölümleri, dar kirişlerin birbirine dik yönde kesiştiği ve üzerinde ince bir levhadan oluşur. Nervürlü tip plakaların avantajları esnek, orta derecede hafif, daha uzun açıklıklar için ekonomik olması, konstrüksiyonun hızlı olması, ince zemin derinlikleri, sağlamlık, mükemmel titreşim kontrolüdür (Baig vd., 2021).

Bina yükleri ve açıklıklar kullanılacak döşeme tipi seçiminde etkilidir. Döşeme tek ve çift yönlü olarak sınıflandırılabilir. Tek yönlü döşeme düz döşemenin en basit biçimlerindendir. Fakat düşük verimliliği ve ağırlığı nedeniyle yalnızca küçük açıklık (4,6 m'ye kadar) için ekonomik olarak kabul edilirler (Timo vd., 2014) Depremler sırasında yapıya etkiyen düşey ve yatay kuvvetlere karşı dayanıklı olması amaçlanan binanın temel bir parçası olan döşemeler ile ilgili literatürde yapılmış çalışmalar bulunmaktadır. Yapılan çalışmalarda döşeme tiplerininin yapılar üzerindeki etkileri araştırılmıştır. Bu çalışmalardan bazıları aşağıdaki gibidir; Qian vd., (2013) yaptıkları çalışmada nervürlü döşemelerde deprem yükünün aktarımı incelemişlerdir ve mevcut nervürlü döşemenin geliştirilmesine yönelik iyileştirme çalışmaları yapmışlardır. Priya vd. (2012) SAP2000 sonlu elemanlar programında kirişsiz döşemeli yapıları modellemişlerdir ve üzerinde statik itme analizi uygulayarak statik itme eğrisi ile talep eğrisi elde etmişlerdir. Çalışma sonucunda mevcut yapının güçlendirilmesine ilişkin daha net karar verilebileceği belirtilmişlerdir. Bhina vd. (2013) boyutları aynı kirişsiz döşemeli ve betonarme çerçeveye sahip simetrik binaları farklı sismik etkiler altında incelenmiş ve betonarme çerçeveli binaların sismik performansının kirişsiz döşemeli binalara göre daha iyi olduğunun sonucuna ulaşmışlardır. Thomas vd., (2017) Farklı döşeme tipleri için yanal yükleme altında diyafram durumunu analitik ve deneysel çalışmalarla değerlendirmiştir. Çalışma sonucunda diyafram durumunun farklı döşeme sistemlerine sahip binaların en boy oranına ve yüksekliğine bağlı olarak değiştiği ve daha küçük en-boy oranına ve yüksekliğe sahip binada hem statik hem de dinamik analizde daha iyi sonuçlara ulaşıldığ belirtilmişlerdir. Malviya ve Tiwari (2021) çalışmasında farklı yüksekliklere sahip iki binayı sonlu elemanlar programı ile modellemişlerdir ve tepki spektrumu analizi ile farklı döşeme tiplerinin deprem etkisi altında yapısal davranışını araştırmışlardır.

\section{Yapının Özellikleri ve Modellenmesi}

Bu çalışmada sismik yükler etkisi altında döşeme tiplerinin bina deprem performansına etkisini incelemek ve bina deprem performansını karşılaştırmak amaçlanmıştır. Bu amaçla kat sayısı 10 olan bir betonarme çerçeveli bina seçilmiştir. Seçilen bina plak döşemeli model (PD) ve Nervürlü Döşemeli model (ND) olarak tasarlanmıştır. Betonarme bina SAP2000 (v21) sonlu elemanlar programı kullanılarak iki farklı şekilde modellenmiştir. Bina taşıyıcı elemanları yönetmeliklere uyun olarak tasarlanmıştır. Kat yüksekliği $3 \mathrm{~m}$, binanın bir yönde uzunluğu $39 \mathrm{~m}$, diğer yönde ise $25 \mathrm{~m}$ dir. Modellenen binalarda beton ve donatı sinıfi olarak C30B420C kullanılmıştır. Plak döşemeli modelde kolonların ve kirişlerin boyutları her katta aynı olup sırası ile $0.35 \times 0.30 \mathrm{~m}$ $0.4 \times 0.30 \mathrm{~m}$ olarak belirlenmiştir. Nervürlü döşemeli modelde kolon, kiriş boyutları her katta aynı olup sırası ile $0.4 \mathrm{x} 0.35 \mathrm{~m}$ $0.4 \times 0.35$ m olarak belirlenmiştir. Burada kolon kiriş boyutları aynı mı, anlaşılmıyor Döşeme kalınlıkları 0,15 m olarak tanımlanmıştır. Bina önem katsayısı $\mathrm{I}=1.0$ olan bu binaların ZB yerel zemin sınıfı üzerinde inşa edildiği kabul edilmiştir. Çerçeve sisteme sahip model için taşıyıcı sistem davranış katsayısı $\mathrm{R}=8$ olarak alınmıştır. Döşemeler üzerinde düzgün yayılı yük olarak $1.5 \mathrm{kN} / \mathrm{m}^{2}$ sabit yük (sıva+kaplama) ve $2 \mathrm{kN} / \mathrm{m}^{2}$ hareketli yük 
dikkate alınmıştır. Kirişler üzerinde $3 \mathrm{kN} / \mathrm{m}^{2}$ duvar yükü (tuğla+sıva) öngörülmüştür. Hareketli yük katılım sayısı $n=0.3$ alınmıştır. Elemanların öz ağırlıkları Sap2000 sonlu elamanlar programına tanımlanarak alınmıştır. Sap2000 programında modeller oluşturulurken kiriş ve kolonlar çubuk eleman, kat döşemeleri shell elemanlar ile modellenmiştir. Modellemelerde döşeme, kirişleri ve nervürü temsil etmek için çubuk elemanlar ile bölünmüştür. Çubuk ve kabuk elemanlar bir ya da daha fazla elemanın kesitini tanımlamaktadır. Her bir çubuk elemanın, kesit özelliklerini ve yüklerini tanımlamak için kullanılan kendi yerel koordinat sistemi vardır. Modellenen binaların kat planları Şekil 1 ve Şekil 2'de verilmiştir.

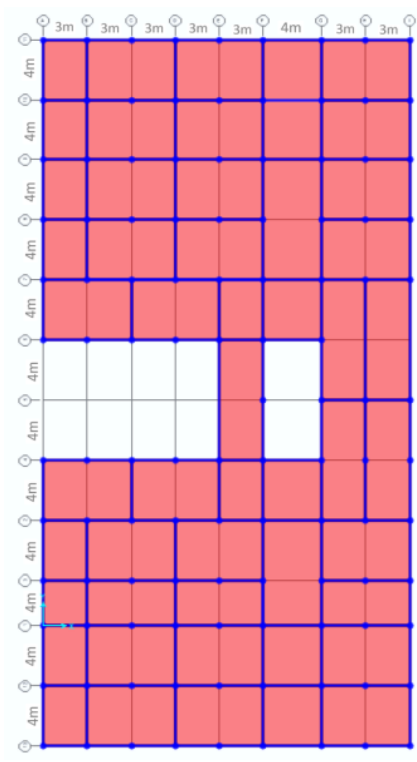

a) Kat Planı

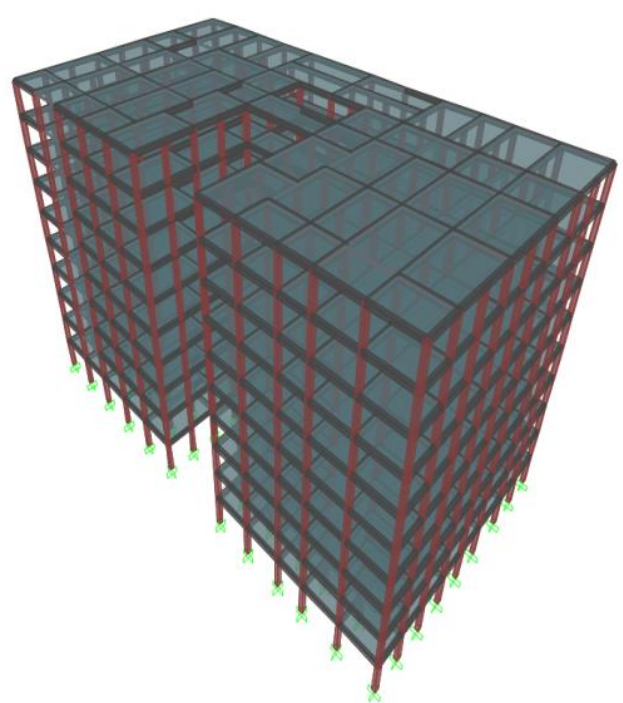

b) Plak Döşemeli model (PD)

Şekil 1. Betonarme Yapının Kat planı ve 3 boyutlu modeli

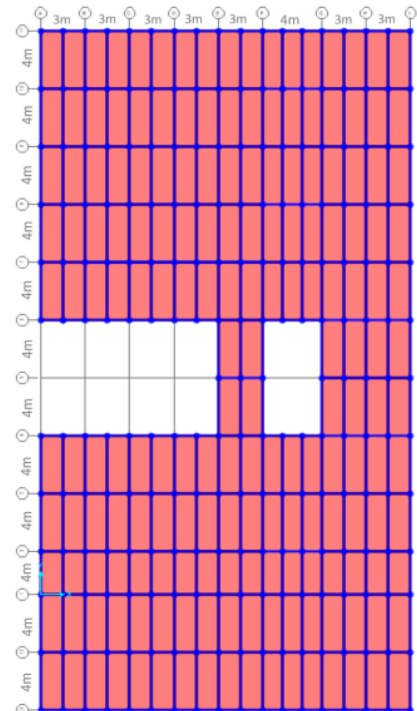

a) Kat Planı

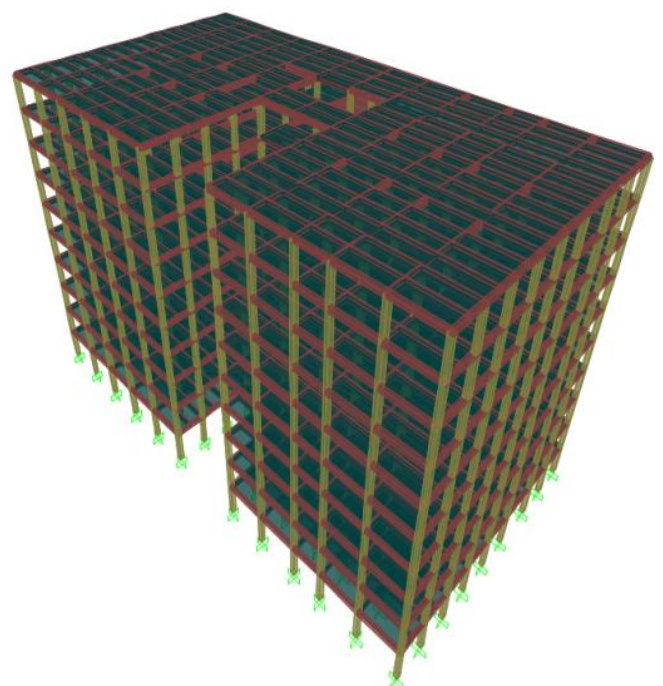

b) Nervürlü Döşemeli model (ND)

Şekil 2. Betonarme Binanın Kat planı ve 3 boyutlu modeli

Şekil 1 ve 2'de gösterilen bina, bir yönde 12 eşit açıklığa ve diğer yönde 8 açıklığa sahiptir. Binalar aynı kat alanlarına sahip olmakla birlikte simetriktir ve her kat 3 metre yüksekliğe sahiptir. İlk model Plak Döşeme ile modellenmiştir. Karşılaştırma amacıyla aynı bina Nervürlü Döşemeye sahip bir şekilde benzer koşullar altında tasarlanmış ve analiz edilmiştir.

\section{Analiz ve Değerlendirmeler}

Çalışmada tasarlanan binaların analizleri TBDY 2018 yönetmeliğinde tanımlı DD2 deprem düzeyine göre yapılmıştır. Reponse Spektrum analiz yöntemi kullanılarak binaların üç 
boyutlu hesap modelleri SAP2000 sonlu elemanlar programı kullanılarak gerçekleştirilmiştir.

DD-2 Deprem Yer Hareketi, spektral büyüklüklerin 50 yılda aşılma olasılığının \%10 ve buna karşı gelen tekrarlanma periyodunun 475 yıl olduğu seyrek deprem yer hareketini nitelemektedir. Bu deprem yer hareketi, standart tasarım deprem yer hareketi olarak da adlandırılmaktadır. Sismik tasarım kodları, sistemin elastik davranışını sürdürmesini ve elastik davranışını koruyarak hasar görmemesini gerektirir. Ayrıca, binanın küçük yapısal hasarlara maruz kalmasının beklendiğgi 50 yıllık geri dönüş süreli daha büyük depremlere maruz kaldığında binanın sismik tepkisini tahmin etmek için de kullanılabilir.

Doğrusal Olmayan zaman tanım alanında analiz için SAP2000 (v21) yazılımında DD-2 deprem seviyesi tepki spektrumu ile uyumlu olacak şekilde SAP2000 yapay deprem kaydı oluşturulmuştur. TBDY DD-2 davranış spektrumu ve yapay olarak oluşturulmuş tepki spektrumu Şekil 3'te gösterilmektedir. Yapay deprem ivme-zaman grafiği ise Şekil 4 'te gösterilmiştir.

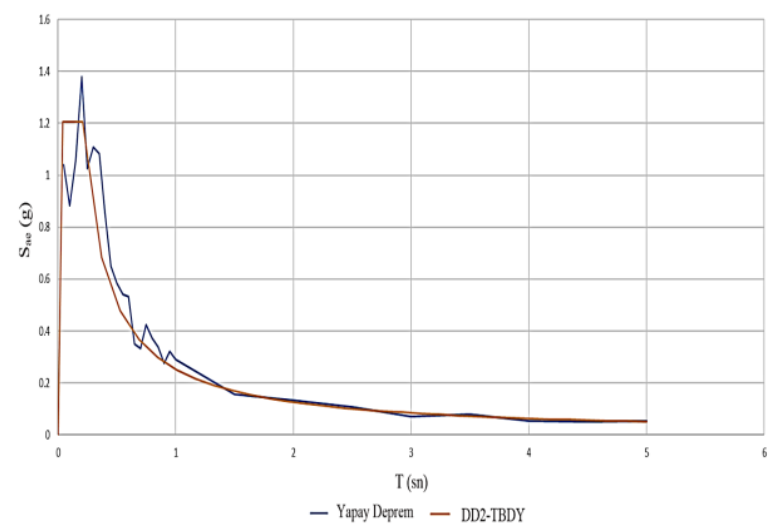

Şekil 3. TBDY2018 tasarım spektrumu ve yapay olarak oluşturulan tepki spektrumu

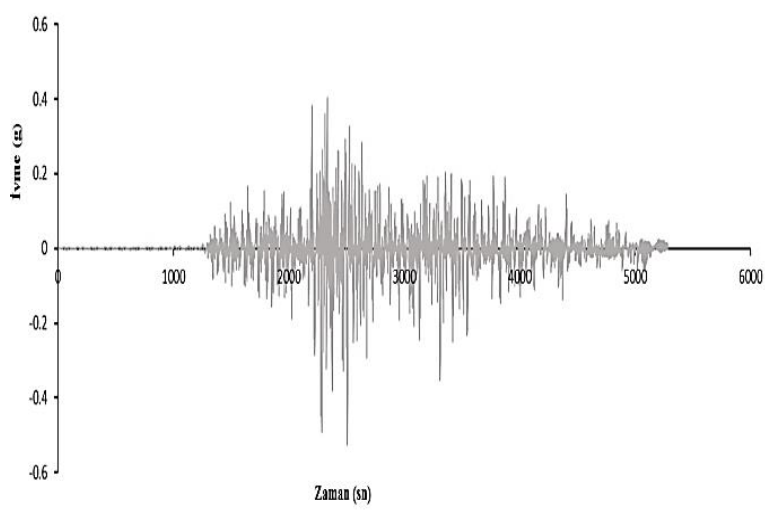

Şeki 4. DD2 seviyesine göre oluşturulan Yapay depremin ivmezaman grafiği

\section{Araştırma Sonuçları ve Tartışma}

Yapı elemanlarındaki yer değiştirmeler, iç kuvvetler ve plastik davranışa sahip elemanların sünekliği, yapıların sismik tepki parametrelerini doğrudan etkilemektedir. Tepe noktası yanal yer değiştirmesi ve katlar arası yanal yer değiştirme (göreli kat ötelemesi), binalardaki döşeme sistemleri için birincil öneme sahip sismik tepki parametresidir. Büyük yer değiştirme değerleri, yapıların stabilitesini ve direncini etkileyebilmektedir. Nervürlü Döşeme sistemleri, katlar arası ötelenmeyi ve yer değiştirmeyi plak döşeme sistemine göre azaltabilmektedir. Ancak burada nervürlü döşemenin daha ağır kütleli olduğunu ve deprem kuvvetlerinin nervür döşemeli sistemlerde daha fazla olduğunu da belirtmek gerekir

Plak Döşemeli betonarme bina ve Nervürlü Döşemeye sahip betonarme binaların zaman tanım alanında doğrusal analizi yapılmıştır. Plak döşeme için elde edilen maksimum eğilme momentleri ve kesme kuvveti sirasiyla $98.69 \mathrm{kN}-\mathrm{m}$ ve $92.86 \mathrm{kN}$ iken, Nervürlü döşemede maksimum eğilme momenti 156.45 kNm ve maksimum kesme kuvveti $128.11 \mathrm{kN}$ olarak bulunmuştur. Ayrıca yapılara ait kat kesme kuvvetleri, kat öteleme değerleri, kat rijitliğii, maksimum yer değiştirme değerleri elde edilmiştir. Elde edilen değerler grafikler sırasıyla Şekil 5, Şekil 6, Şekil 7 ve Şekil 8'de gösterilmiştir.

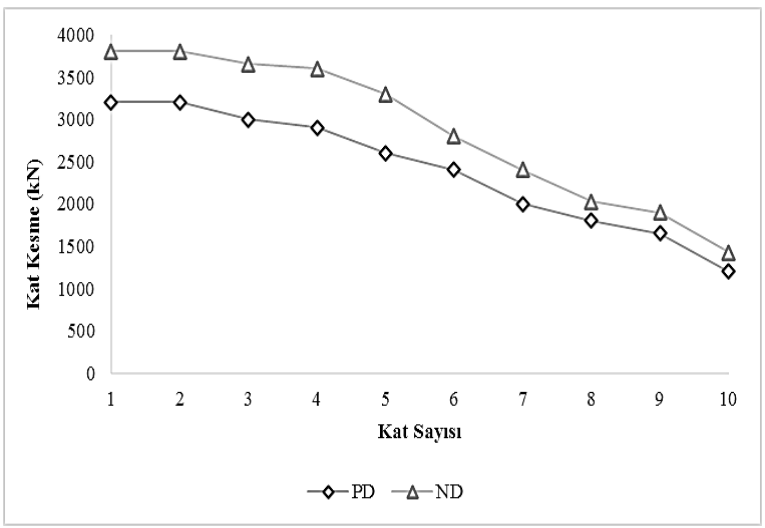

Şekil 5. plak döşeme ve nervürlü döşemeli betonarme binanın kat kesme kuvvetleri

Binanın katlarına gelen kesme kuvvetleri incelendiğinde daha fazla ağırlığa sahip olan nervürlü döşeme yapısında plak döşeme yapısına kıyasla daha fazladır.

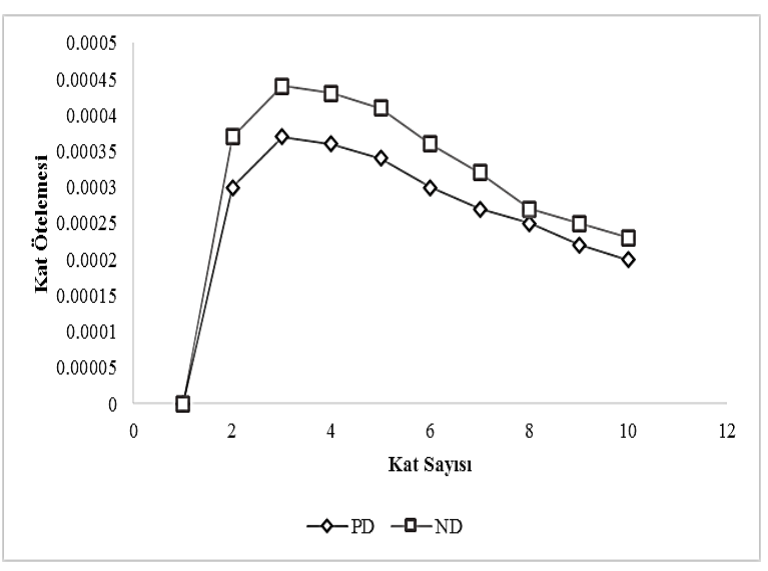

Şekil 6. plak döşeme ve nervürlü döşemeli betonarme binanın kat ötelemesi

Her iki binadan elde edilen göreli kat ötelemesi değerleri incelendiğinde binalardan elde edilen değerlerin yönetmelikte izin verilen maksimum etkili kat ötelemesi oranı sınır değerler içerisinde kaldığı görülmektedir. Bunu gösterelim Maksimum etkin göreli kat ötelemesi oranı her iki döşeme yapısına sahip binada modellerin 3. katında meydana gelmiştir. Değerleri plak döşemede 0.00036 , nervürlü döşemeli yapıda ise 0.00043 olarak hesaplanmıştır. $\mathrm{Bu}$ değerleri tabloda gösterelim Nervürlü 174 
döşemeden elde edilen etkin göreli kat ötelemesi değerleri geleneksel yapıdan elde edilen değerlere yakın olmakla birlikte daha fazladir.

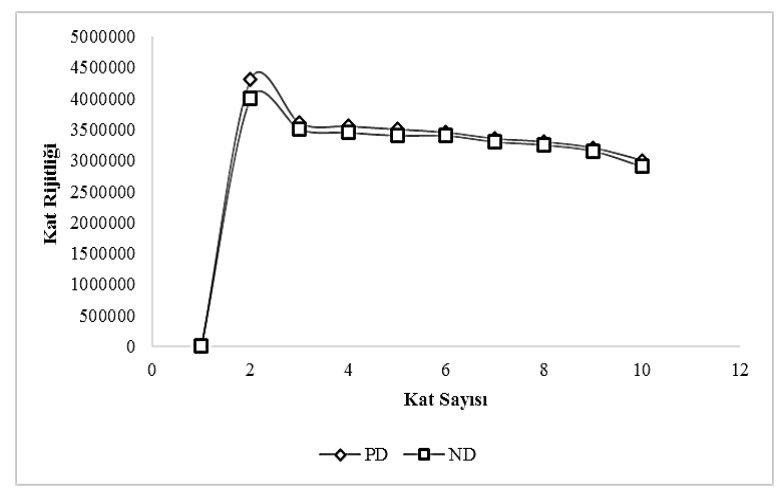

Şekil 7. plak döşeme ve nervürlü döşemeli betonarme binanın kat rijitliğ $i$

Kat rijitliği, nervürlü döşeme yapısında daha az kolon olduğundan normal döşeme yapısı için biraz daha fazladır. En büyük kat rititliği modellerin 1 . katında meydana gelmiştir ve değeri plak döşeme için $4300000 \mathrm{kN} / \mathrm{m}$, nervürlü döşeme için ise $4000000 \mathrm{kN} / \mathrm{m}$ olarak hesaplanmıştır.

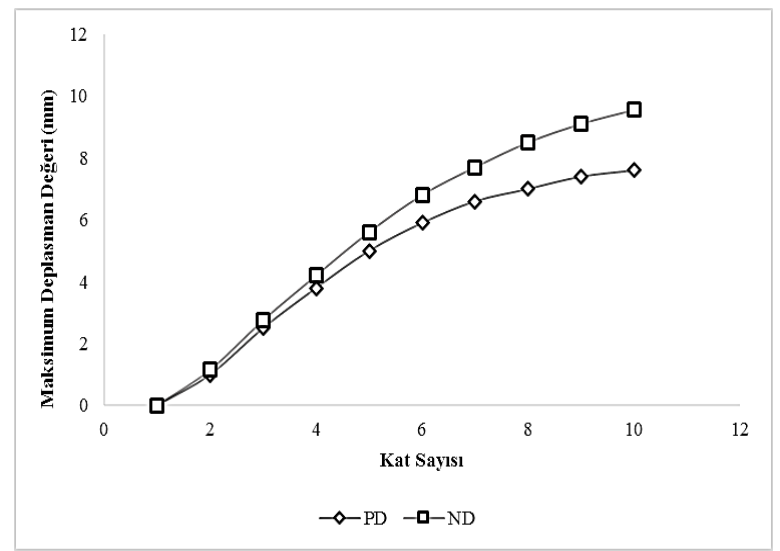

\section{Şekil 8 plak döşeme ve nervürlü döşemeli betonarme binanın tepe noktası maksimum yer değiştirme değeri}

Her iki binadan elde edilen maksimum yer değiştirme değerleri kıyaslandığında diğer değerlere benzer şekilde nervürlü döşemede maksimum yer değiştirme değeri daha yüksek bulunmuştur.

\section{Sonuç}

Ülkemiz kara alanının yaklaşık \%92'si zarar verici seviyelerde sismik tehlikeye karşı hassastır. Gelecekteki depremlerden kaçınamayız, fakat hazırlıklı olma ve güvenli bina inşaat uygulamaları ile hasar ve kayıpların boyutunu azaltabiliriz.

$\mathrm{Bu}$ çalışmada; betonarme yapıların taşıyıcı sistemlerinde betonarme döşeme elemanlarının yapıların deprem performansına etkileri incelenmiştir. 10 katlı bir betonarme çerçeveli bina plak ve nervürlü döşeme olmak üzere iki farklı şekilde Sap2000 sonlu elemanlar programında modellenmiştir. Hesaplar için DD-2 seviyesine göre yapay deprem kaydı oluşturulmuş ve binaların doğrusal zaman tanım alanında analizleri yapılmıştır. Modellerde kolon ve kirişler için yönetmelikte belirtilen rijitlikler kullanılmıştır.
Modeller değerlendirildiğinde plak döşemeye sahip model, nervürlü döşemeli model ile kıyaslandığında daha yüksek rijitliğe sahiptir.

Nervürlü bir döşeme yapısı üzerindeki yanal yükler, kendi ağırlığının artması nedeniyle plak döşeme yapısına göre daha fazladir.

Plak döşemeli sistemelerin, yüksek diyafram rijitliğine, gerekli yanal direnç ve ötelenme rijitliğine sahip olması yapının sünekliğine önemli mertebelerde etki etmektedir ayrıca bu durum modal analiz sonuçlarını da etkilemektedir. Nervürlü döşemeler plak döşemeler ile kıyaslandığında farklı rijitliğe sahiptir ve daha ağırdır. Diş doğrultusunda yeterli rijitlik söz konusu iken dişe dik doğrultıdaki kirişlere dişler oturmadığından bu yönde yeterli riğitliğin sağlanmasında sorun yaratabilecektir.

Nervürlü döşemeye sahip binada deprem yüklerinden oluşan kat kesme kuvvetleri plak döşemeli binaya kıyasla \%22 artmıştır. Nervürlü döşeme binasının kendi ağırlığı plak döşemeli binaya göre daha fazla olduğundan bu modele gelen deprem kuvvetleri daha fazla olmuştur. Nervürlü döşeme binasında maksimum yatay yer değiştirme plak döşeme binasının \%23'ü kadar artmıştır.

Çalışmadan elde edilen sonuçlar dikkate alındığında deprem bölgelerinde nervürlü döşemelerin deprem yüklerine karşı iyi bir performans sergileyemediği sonucuna varılmıştır. Bu bölgelerde deprem yükleri plak döşemelerin kullanımı ile daha güvenle karşılanabilir. Ancak binanın çeşitli yöntemlerle güçlendirilmesi ile nervürlü döşemeli binaların deprem performansını arttırılabileceği göz ardı edilmemelidir.

\section{Kaynakça}

Aral, M., \& Tunç, G., (2021). Türkiye'de Deprem Performansına Dayalı Bina Kimlik Bilgilerinin Oluşturulmasına Yönelik Çalışma ve Öneriler. Afet ve Risk Dergisi, 4(1), 20-41.

Arman, I.M. (2014). Analysis of two-way ribbed and waffle slabs with hidden beams. International journal of Civil and Structural Engineering, 4(3), 342-352.

Baig, M. M., Rashid, A., Reddy, Y., \& Krishna, T. V. (2021). A comparative study on seismic analysis of $\mathrm{G}+6$ building with ribbed slab \& conventional slab using SAP2000 software. In IOP Conference Series: Materials Science and Engineering, 1112(1), 012026.

Bhina, M.R., Banerjee, A., \& Paul, D.K., (2013). Assessment of different aspects of RC flat-slab building over normal RC frame building, International Conference on Structural Engineering and Construction Management, At Sri Lanka.

Bikçe, M., \& Akyol, B. (2017). Tasarlanmış gerçek yapılarda asmolen/plak döşeme dönüşümünün yap1 maliyetine etkisi. Furat Üniversitesi Mühendislik Bilimleri Dergisi, 29(1), 133-144.

Costa, Y., \& Araújo, T. (2014). Evaluation of dynamic behavior of waffle slab to gym center. Latin American Journal of Solids and Structures, 11(7), 1114-1131.

Malviya, S., \& Tiwari, M. (2020). Behaviour of Flat Slab, Waffle Slab, Ribbed \& Secondary Beam in a multistorey Building under Seismic Response: A Review. 8, 986-992.

Middleton, C.J., Brownjohn, J.M.W., (2010). Response of frequency floors: a literature review. Engineering Structures, 32, 337-352.

Priya, K.S., Durgabhavani, T., Mounika, K., Nageswari, M., \& Poluraju, P. (2012). Non-linear pushover analysis of flat slab 
building by using SAP2000, International Journal of Recent Technology and Engineering (IJRTE), 1(1), 29-33.

Qian, K., Dong, G. Y., Zhang, J., \& Yuan, Q. (2013). Study on the Effect of Grid Beam on Seismic Performance of Improved Multi-Ribbed Slab Structure. In Advanced Materials Research.724, 1754-1758.

Thomas, E., George, J., \& Paulose, D. (2017). Assessment of the Diaphragm Condition For The Floor Systems. 4(6), 836-843.

Timo K. T., \& S. Ali Mirza. (2014). Effective Length of Reinforced Concrete Columns in Braced Frames. International Journal of Concrete Structures and Materials, 8(2), 100-106.

Usta, P., \& Bozdağ, Ö. (2021). Tarihi Başdurak Camisinin Deprem Analizi. Pamukkale Univ Muh Bilim Derg.; 27(3): 244-250 | DOI: $10.5505 /$ pajes.2020.31384 